\title{
Review of Overseas Communication of Chinese Internet Literature
}

\author{
Song Jiaojiao, Duan Youguo*
}

School of Foreign Studies, Yangtze University, Hubei, 434023 PRC China

*Corresponding Author

Received: 08 Sept 2020; Received in revised form: 12 Nov 2020; Accepted: 24 Nov 2020; Available online: 07 Dec 2020 (C)2020 The Author(s). Published by Infogain Publication. This is an open access article under the CC BY license (https://creativecommons.org/licenses/by/4.0/).

\begin{abstract}
In recent 20 years, China's Internet literature has developed rapidly. Especially under the background of Chinese literature going out. It has accelerated the pace of overseas dissemination, first regarding Southeast Asia as the regional hot spot, and then radiating to Europe, America and other countries. Relevant studies have found that, as a new thing, Internet literature has also faced many difficulties during its dissemination, such as poor translation quality, rampant piracy, single subject, and different overseas standards. Therefore, it requires not only non-governmental organizations to consciously increase the market vitality, but also the national support to help Chinese Internet literature actively "go out". We should strengthen the content review and screening of overseas Internet literature, enhance the protection of multi-channel copyright, pay attention to multi-level copyright operation, and carry out an all-round overseas layout.
\end{abstract}

Keywords-Chinese Internet literature, overseas communication, Chinese online novels, difficulties, countermeasures.

\section{INTRODUCTION}

The network revolution takes place all over the world, but the Internet literature has a unique scenery in China. Some people even think that Chinese Internet literature is a "world cultural wonder" comparable to American Hollywood, Korean TV series and Japanese animation. Although it might be a little exaggerated, it has to be admitted that the development speed of Chinese online literature is staggering. In the past four years, many Chinese scholars have paid attention to the Internet literature and the overseas dissemination of Internet literature. They have found that not only in China itself, but also in overseas, Chinese Internet literature is attractive. By means of CNKI(China National Knowledge Infrastructure), one of the most influential databases in ISSN: 2456-7620
China, this paper set the key words as "Internet literature + external communication", "Internet literature + going out" and "Internet literature +overseas" 30 and 43 documents were collected respectively through the preliminary topic screening and review of abstracts. According to the analysis of the earliest publishing time, it can been seen that the earliest published articles about "Internet literature + external communication" and "Internet literature + overseas" were published in 2017 , only the articles on "Internet literature + going out" were published in 2014, based on which, it is safe to say that the overseas dissemination of online literature has attracted people's attention in recent four or even nearly seven years. The visualization analysis of CNKI explains the number of published articles is on the rising trend as a whole. 
However, there is no general overview of the overseas development status and difficulties of Chinese Internet literature. Therefore, this paper hopes to make a clearer understanding of its overseas development by combing the development status, difficulties and Countermeasures of Chinese Internet literature in different overseas countries.

\section{THE ORIGIN AND DEVELOPMENT OF INTERNET LITERATURE}

Literally, Internet literature is a kind of literature that depends on network communication. Different Chinese scholars have their own opinions on it. Most of them hold positive opinions on Internet literature, but some hold a skeptical attitude. As a new thing, it is justifiable to be questioned. Among them, Shang (2009) questioned the correctness of the statement of Internet literature. He thought that literariness of writing is composed of the nature of writing themselves, and literariness of words is related to the writer's emotional thinking ability, the level of words, etc., and has nothing to do with the medium on which the words are written. Similarly, whether writing is literary or not does not rely on whether they are written on manuscript paper or typed by computer.

It is known that computer originated in the west and Internet literature attached to the Internet, so its earliest appeared in the West. Influenced by the western Internet literature, Chinese Internet literature also emerge as the times require. In the 1980s, China began to implement the basic national policy of Reform and Opening up. In order to respond to the call of the state, a group of young people with aspirations studied abroad. Among them, some studying in North America are the first to contact the Internet. They are nostalgic for their hometown and love for their motherland, but they suffer from the lack of expressing feelings and communicating their mother tongue. Therefore, they have set up various websites to make use of the convenience of the Internet to quickly share resources and post on the Internet to exchange feelings. Thus, the rudiment of Chinese Internet literature began to appear (Ouyang, 2018). Later, some college students who love literature began to post the overseas online literature with which they could came into contact on the BBS of Chinese universities, and a group of college students with certain literary background began to publish their literary works on BBS. At the end of the 1990s, the works of the first Close Touch from Cai Chiheng and Live like a Man from Lin Yusen, were popular in the mainland, which caused a number of outstanding mainland traditional writers to "surf the Internet" one after another (Xu, 2002). As a result, Chinese Internet literature has taken root and flourished in the mainland, and various online novel platforms are everywhere.

\section{OVERSEAS DEVELOPMET OF CHINESE INTERNET LITERATURE}

Due to regional and cultural commonality, China's Internet literature is very popular in East and Southeast Asian countries and regions, including South Korea, Japan, Thailand, Malaysia, Vietnam, etc. (Li, 2019), especially Vietnam. At the beginning, all these countries bought copyright from China. Among them, Starting Point Chinese Net has sold copyrights to other countries since 2004. In 2006, representative works such as Candle in the Tomb and Jade Dynasty were translated into Vietnamese. (Tan, 2019) One year later, Zhuang Xia, a Vietnamese student who had studied in China, was the first person to translate Bao Qi's novels into Vietnamese, which triggered their pursuit and real-time tracking translation of Chinese Internet literature (Gao, 2017). In 2011, Jinjiang Literature City signed the first Vietnamese copyright contract, which has cooperated with more than 20 Vietnamese publishing houses by 2015(Li, 2015). According to Vietnamese Youth Daily, the number of Chinese books translated into Vietnamese from 2009 to 2013 exceeded that of Japan and South Korea that have similar culture with China, reaches 841. Among them, 617 are translated from Chinese Internet literature and 74 are pure literature, accounting for $73 \%$ of the total amount of translation and publication (He \& Wang, 2015; Dong \& Liu, 2017). It can be seen that Chinese literature, especially the recent Chinese internet literature, has had a profound impact on Vietnamese.

According to the report from People's Daily Overseas Edition (Li, 2015), since 2012, only South Korean Paran 
Media publishing house has successively purchased the copyright of three works, Startling by Each Step, Ballad of the Desert and YunGe from the Desert, and Startling by Each Step is very popular in South Korea. Since 2011, Thailand, Singapore and other countries have also cooperated with Jinjiang literature City to translate and publish Chinese online literary works, such as Internet novels like The Journey of Flower. On August 24, 2017 , iReader signed an agreement with Thailand Hongsamut. Nine Chinese Internet novels will be translated into Thai on Hongsamut's website for local readers to pay for reading. In the future, 40 Chinese Internet novels will be exported to Thailand (Zhang, 2017). As of April 2019, on Chinese Publication Exhibition Tour in Southeast Asia, the key project of Silk Book Project undertaken by Xiamen International Book Company Limited; Thailand alone signed more than 400 copyright trading projects with Chinese publishing institutions (Zhu, 2019). The development of Chinese Internet literature in Thailand has accelerated. On the one hand, it benefits from both sides' joint selection of original literary themes of high quality and in line with the taste of Thai readers. On the other hand, thanks to China's good stories, good stories always get attention and love.

Different from the popular historical and romantic Internet novels in Southeast Asia, the themes of Chinese Internet literature rising among American and Canadian students are basically Xianxia, Qihuan, and Xuanhuan novel. (Liu \& Duan, 2020) Chinese Internet Xuanhuan novels initially attracted English readers' interests by serializing them on Japanese and Korean Light Novel websites (Chen, 2018), but they did not attract much attention. We have to mention a man, Lai Jingping, who has made a great contribution to the spread of Chinese online novels in North America. He is a Chinese American, whose pseudonym is RWX adopts the initials of the character's name in The Smiling, Proud Wanderer from Jin Yong. At first, on the Spcnet forum, one of the strongholds of Japanese and South Korean Light Novel website, he noticed that a Chinese Vietnamese named he-man translated Stellar Transformations. As a result, he became interested in another novel, Coiling Dragon, written by the author I Eat Tomatoes, and tried to translate it. Later, Coiling Dragon attracted more and more people. On December 22, 2014, he founded Wuxiaworld, which is still the main position of Chinese online

Novels in North America(Ji ,2016). Therefore, from the beginning North America embarked on a path quite different from the Southeast Asian countries that purchase copyright. In addition to Wuxiaworld, the world's first Internet literature translation website, there are Gravity Tales, an original website founded by GGP in December 2015, and Volare Novels which was founded by Etvolare, an Taiwanese American, to translate alternative works (spoofs, sci-fi, etc.) and the girl channel novels.(Bao, 2018; Chen, 2017)

According to the global Alexa website query, it is estimated conservatively that the number of visitors per day to access Wuxiaworld is more than 2 million, so it could show Chinese Internet novels are popular in Europe and America. Guo (2017) analyzed that there are three reasons for the "European and American Heat" caused by Chinese Internet literature: "firstly, Internet literature accurately grasps the reading expectation and aesthetic taste of overseas audiences." A close look at the translation of Coiling Dragon by RWX shows that its background setting and characters' names are very similar to the western traditional magic literature, which can produce a sense of substitution. In addition, mixed oriental mystery makes the Western readers both familiar and unfamiliar, which has generated great interest in it. "Secondly, Internet literary works are highly translatable." In an interview with Shao Yanjun and Ji Yunfei, Lai once said that his early translations of Jin Yong's and Gu Long's novels were difficult to be accepted in the West because they were too Chinese. However, the content of Internet literature works is simple, easy to read, language expression is easily understood, foreign readers can easily and quickly read them. "Thirdly, online media is more in line with the social needs of people in modern society." Internet novels facilitate readers to use fragmented time to read and interact with writers, which makes readers have a sense of participation and will devote themselves to Internet novel reading with greater enthusiasm. 


\section{DIFFICULTIES AND COUNTERMEASURES OF OVERSEAS COMMUNICATION OF CHINESE INTERNET LITERATURE}

Although Chinese Internet literature has caused quite a repercussion overseas, even an American young man Kevin Cazad successfully quit his addiction to drugs after reading Chinese Internet novels for half a year, there are still many difficulties in the process of overseas dissemination of Chinese Internet literature. Many scholars believe that there are translation problems (Cao, 2019; Bao, 2018; Lv, 2020), platform operation problems (Xi \& Fu, 2018; Dong \& Liu 2017; Chen, 2019), copyright issues (Li, 2019; Lin, 2019; Zheng, 2018), and communication content (He, 2019; Yang, 2018; Li, 2019).

If Chinese Internet literature wants to spread overseas, the first and indispensable step is translation. Only after translation can foreign readers read it. However, due to the lack of talented translators (Cao, 2019), especially due to the particularity of network language and the characteristics of Chinese culture, which increases the difficulty of translation. Internet language types are complex and constantly changing, with too many original words and new expressions(Bao, 2018). It is no less than deep-water bombs for translators when facing the authors' free creation, inspiration and meaningful or funny wordings and sentences. Moreover, most of these works have profound cultural background and rich historical color, hence it is difficult to find the corresponding words for some words with profound cultural connotations and terms of ancient industries in the translation process. (Bao, 2018) If the translator only has a sense of affinity for Chinese culture of ethnic Chinese and foreign friends who are not familiar with Chinese culture, which is very difficult for translators. Therefore, a good translation requires a high level for translators, but good translators are much less than good works. In addition, on the one hand, most translators engaged in online translation are part-time translators, unable to balance full-time work and part-time translation; on the other hand, the income of part-time online translation mainly relies on reward, crowdfunding and platform subsidy, which leads to the scarcity of translators. (Lv, 2020)
It is necessary to improve the quality of translation, but the most important thing is to improve the translator's translation ability (Gao, 2017). Therefore, it is essential to increase the training of translation talents and related funds, optimize and improve the translation team, and strengthen the initiative and consciousness of the external promotion of Internet literature (Chen, 2019). The cultivation of translation talents who translate Chinese into other languages should not only rely on the government and universities, but also mobilize various positive factors such as gathering folk translation lovers, foreign language training institutions and translation training institutions in the society through the Internet. The Chinese government has set up cultural activities such as "Confucius Institute", "World Chinese Conference" and "Chinese Culture Year" all over the world. There are more and more foreign friends learning Chinese and Chinese culture, which is a force that cannot be ignored by C-E translators in the future. (Cao, 2019)

After the translation is completed, the dissemination of the translated works overseas also needs to use the network platform to spread. For an active non-governmental translation website like Wuxiaworld, folk translation enthusiasts voluntarily undertake translation work out of interest and mission. So the platform has the characteristic with a single operating model, mainly profits from advertising, rewards and crowdfunding (Xi \& Fu, 2018), which has a certain degree of ambiguity and uncertainty in profitability, and is prone to lag in update and supply, thus affecting the stable output (Dong \& Liu, 2017). It can be seen that Chinese Internet literature has not yet formed an effective and sustainable profit model in the overseas market (Chen, 2019). If we keep the situation that translators have no income and platforms have no source of funds, their passion and desire for work will fade, and the platform cannot support its operation, so it will be difficult to maintain a prosperous situation for a long time. Based on such a situation, $\mathrm{Xi}$ and $\mathrm{Fu}$ (2018) believe that Internet literature should actively "go out" and cannot wait for others to "take it". The spontaneous and small workshop-style mode of reward has great uncertainty. If China Internet literature actively participates in the competition of translation, 
dissemination and IP incubation in the overseas Internet literature market, it will be a win-win situation for overseas to obtain stable, high-quality and continuous translations, and for China to select and disseminate the excellent works conforming to the historical and cultural traditions of China and the new folk culture in the new era, and reflecting the spirit of the times.

It's a pity that most of the Chinese online works spread abroad have not passed through formal channels, and piracy is rampant. Some studies have shown that the number of online literary works entering other countries through formal channels is only equivalent $5 \%$ of that of illegal channels.(Li Qiang, 2019) Lin Tingfeng (2019), senior vice president of China Literature, also indicates that the biggest challenge of Internet literature overseas is piracy. At present, most of the overseas translation platforms are not authorized by the original authors and their online platforms. Although the copyright companies of Chinese original works such as China Literature Limited have successively reached authorization and cooperation agreements with several overseas translation platforms, the vast majority of overseas translation websites have not yet obtained the translation authorization (Zheng, 2018). There are two forms of piracy and infringement in the dissemination of Chinese domestic Internet literature (Xiao, 2017), which are also applicable to the overseas dissemination of Chinese Internet literature. One is that the website itself knows its activities are infringements but still illegally reprints novels, which involves direct infringement. For example, according to the statistics from He Mingxing, the executive director of the Effect and Evaluation Center of Chinese Culture Going Out, among the 841 kinds of books translated and published in Vietnam, apart from some well-known works, a considerable part are pirated works that have not been authorized by most Chinese literature websites. Due to the urgent need of content resources, some Vietnamese publishing institutions employ Vietnamese students in China and some Chinese people from Guangxi, Yunnan and other provinces to obtain publishing resources directly from China's major literature websites. After translation, adaptation and rewriting, a length is suitable for Vietnamese readers, it will be published in the name of
Chinese authors (Zhang, 2016). The second is that the network platform only serves as a network service provider with no profit-making purpose. For example, Wuxiaworld only shared Chinese Xuanhuan novels with foreign readers in the early stage, and then there was a reward model as a profit-making method in the later stage.

As for the proliferation of infringement and piracy, Bao (2018) suggested that we should strengthen the content review and screening of overseas Internet literature, enhance the protection of multi-channel copyright, pay attention to multi-level copyright operation, and carry out an all-round overseas layout. Therefore, facing different situations of piracy and infringement, different methods should be adopted to deal with them. Malicious network piracy acts such as they have already know it's an infringement can be severely punished through international intellectual property cooperation and other channels, but for some non-profit-making piracy infringement, copyright cooperation, joint operation and other ways can be adopted. The state should strengthen the linkage of judicial and administrative governance, carry out in-depth special work, crack down on infringement and piracy, provide guide and support with legitimate payment, establish copyright content database and blacklist of pirated websites, and maintain a good copyright order (Cao, 2019). Li (2019) put forward more specific and constructive plannings that require local cultural departments to conduct preliminary statistics on Chinese Internet literature writers, Chinese registered literature websites and Internet literary works with large reading volume, and generate information materials. Then, the government guides the establishment of Network Culture Office, which is specially responsible for the dissemination and management of overseas network literary works. The network culture office cannot charge any intermediary fees from authors, publishers or websites. All the funds are borne by government departments until the local Internet literature is gradually standardized. From the perspective of Chinese original network platform, the copyright awareness of the whole network platform industry needs to be improved to crack down on piracy and put an end to infringement. (Xin, 2019) 
At present, more than 500 Internet literary works have been translated into "overseas" (He, 2019). However, according to the popular ranking list of overseas websites, most of them are Xuanhuan and Xianxia themes so it is very obvious that the themes are blankness. Besides, a large number of Xianxia works adopt similar "novels routine", which will inevitably cause readers' aesthetic fatigue on the novels in the long run. (Yang, 2018) The content with low creativity is homogenized, hollow and commercialized seriously. Most of the works are divorced from history and reality, which are worlds imagined by the authors out of thin air, unable to bear the value connotation of literary creation reflecting the spirit of the time. If without era resonance, Internet literature will lose its vitality. (Xi \& Fu, 2018). There are obvious differences between traditional literature and Internet literature that is criticized as "spiritual drug". Therefore, after some literary works spread overseas may not be able to give full play to the pivotal role of literature, such as unable to reflect social reality, transmit correct and positive information, and fail to guide the formation of right readers' values $(\mathrm{Li}$, 2019). This is Achilles' heel of long-standing development and predicament of Internet literature.

This phenomenon is also because of variable quality of the original text in China. Xiao (2017) believes that the original text's quality should be controlled from the source. Novel websites should play the role of "gatekeeper" who can strictly ensure the quality of literary works, put an end to the spread of "junk literature", restrict the publication of novels of the same type, and guide network writers to break through the shackles to create in many new ideas. However, among China's major reading websites, only the Starting Point Chinese Net and Xiaoxiang website have opened the scoring function. What's more, it has certain reference value but with many limitations because scoring is lack of objective. Tang (2019) tends to establish a third-party online novel rating website, which is a better choice. Xi and Fu (2018) also agreed that a sound network criticism system should be established and the excellent criticism theory of traditional literature should be used for intervention. No matter which mode is adopted, it cannot be established overnight, but once successfully applied to the operation system, it will certainly promote the better development of Internet literature.

\section{CONCLUSION}

With the development of media technology, the spread of online novels is faster and wider. In addition to Southeast Asia and East Asia, which are close to China, and Europe and America where Internet novels are popular, Chinese Internet literature has also been continuously transmitted to minor language countries such as Germany, Spain, Hungary, India, Sri Lanka and so on. Although the Internet literature still faces some problems, like piracy, plagiarism, serious homogenization of content and single theme, it does not hinder China's continuous delivery of excellent works to overseas countries. It is believe that as long as China can cultivate high-quality translators, establish and improve the network platform, improve the legislation, establish a strict audit system, and create a good communication environment, the overseas dissemination of Chinese Internet literature will still be infinite possibilities to become a Chinese industry comparable to American Hollywood, Korean TV series and Japanese animation in the future.

\section{REFERENCES}

[1] Shang, J. (2009), My query on "Internet literature". Network Communication. (2): 90-91

[2] Ouyang, Y. Q. (2018), The rise of Chinese network literature in this age. InternetLiterature Review. (6): 5-13

[3] Xu, M. W. (2002), Origination and development of China's network literature. Journal of Jianghan Petroleum Institute (Social Science Edition), 4 (1): 71-74

[4] Li, Q. (2019), Predicament and outlet of overseas communication of Chinese Internet literature. Journal of Kaifeng Institute of Education. , 39(1): 34-35.

[5] Tan, J. Y. (2019), A brief analysis of the course, characteristics and trend of Internet literature going abroad. Journal of Beijing Institute of Graphic Communication, 27(2): 28-32.

[6] Gao, C. J. (2017), Research on overseas translation and export of Chinese Internet literature. A Vast View on Publishing (2): 90-91 
[7] Li C. Q. (2015), Internet literature go out the scenery in China is unique, People's Daily Overseas Edition, 8015-1-6.

[8] He, M. X., Wang, D. N. (2015), Communication model under cultural proximity: translation and publication of Chinese Internet literature in Vietnam, China Publishing Journal, (12): 56-60

[9] Dong, Z. M., Liu, X. (2017), New ways for exporting of Chinese culture--introduction and thoughts on the exporting of Chinese Internet literature, Editorial Friend, 2017 (8): 17-20.

[10] Zhang, H. (2017), The Belt and Road initiative arouses a craze, China Daily 2017-08-26.

[11] [11] Zhu, Li. Na. (2019), China's publishing industry goes global: its pace is accelerating, China Media Group, 2019-12-23

[12] Liu, H., Duan, J. L. (2020), Analysis of regional differences in copyright export of Chinese

Internet literature. View on Publishing, (02):48-50

[13] Chen, X. C. (2018), Chinese wen fictions going global from the perspective of readers' response--A translation study of Battle through the Heavens, Fujian Normal University.

[14] Ji, Y. F. (2016), Conquering North America and going Global: Why do foreigners love Chinese Internet novels, Theory and Criticism of Literature and Art, (6): 112-120.

[15] Bao, X. (2018), Problems and countermeasures of current network literature going to sea, China Publishing Journal, (10): 28-31.

[16] Chen, C. H. The enlightenment of the popularity of Chinese Internet novels overseas, International Communications, (11): 35-37.

[17] Guo, J. (2017), Talk about Chinese literature translation and publishing go global_ take European and American heat of Chinese Internet literature as an example, View on Publishing, (3): 85-87.

[18] Cao, W. G. (2019), The Overseas Communication of Chinese Internet Literature--A Case Study of the Internet Novel Lang Ya Bang, Journal of Hunan Institute of Engineering(Social Science Edition), 29(2): 27-31.

[19] Lv, Z. Y. (2020), Research on overseas Communication of Internet Literature under the background of cross-cultural Communication, New Media Research, 6(17):78-80.
[20] Xi, Z. W., Fu, Z. Q. (2018), Predicament and outlet of overseas communication of Chinese Internet literature, Chinese Editorials, (4): 79-84.

[21] Chen, J. J. (2019), Thoughts on the overseas transmission of Internet literature, China Culture Daily, 2019-6-19.

[22] Lin, T. F. (2019), The world dissemination of Chinese stories - Overview of overseas communication of Chinese network literature (2001-2018), Internet Literature Review (1): 45-50.

[23] Zheng, J. W. (2018), A study on the overseas reception and Internet translation mode of Chinese Internet literature, Literatures in Chinese, (5): 119-125.

[24] Xiao, H. (2017), Analysis of the transmission mode of Internet novels with Starting Point Chinese Net as an example, Dissemination and Copyright, (11): 67-69.

[25] Zhang, H. (2016), Chinese Internet literature breaks out of the China and creates a Chinese-style "Hollywood", China Daily, 2016-12-05

[26] Xin, F. (2019), Research on the current situation and countermeasures of overseas dissemination of Chinese Internet literature, Satellite TV \& IP Multimedia, (10): 108-110.

[27] He, X.Y. (2019), China's digital reading market reaches 25.45 billion yuan, People's Daily Overseas Edition, 2019-11-29.

[28] Yang, W.T. (2018), SWOT analysis and strategy research on overseas communication of Chinese Internet literature, Research on Transmission Competence, 2(10): 185-186.

[29] Tang, F. Y. (2019), Bottlenecks and breakthroughs in the English translation of Chinese Internet novel, English Square (Academic Research), (3): 59-61. 